\title{
The significance of shape in cartographic communication
}

\author{
Silvia Klettner \\ Vienna University of Technology, Research Division Cartography, Vienna, Austria; silvia.klettner@tuwien.ac.at
}

Keywords: Visual communication, Semiotics, Perception, Thematic cartographic representations

\begin{abstract}
:
Human communication is notable both for its precision and flexibility (Krauss, 2002). By following a mutually shared set of signs and rules, meaning can be conveyed from one entity to another. In doing so, human communication allows to formulate an "unlimited number of meaningful novel messages that are not tied to the immediate present" (Krauss, 2002, p.1). Human language in particular allows to refer to and think about both concrete objects and abstractions, past events and experiences, remote both in space and time, or which exist only in the imagination (Keates, 1996). The same applies to visual communication. However, despite their similarities, maps are unlike language. Its elements are unlike words, but independent associative symbols with a reference fixed by convention but not by a single, nor unequivocal reference (Bertin, 1974; Langer, 1953; Wood, 2010; MacEachren, 1982).
\end{abstract}

At the same time, humans constantly respond to their environments and the stimuli therein, responding differently in respect to the type and characteristics of the stimuli exposed to (Russell, 1980; Russell \& Feldman Barrett, 1999). Applying this perspective to cartography indicates that the choices on how to depict and express data will affect how a map is perceived and interpreted (Monmonier, 1996). Thus, cartographic elements and their visual parameters (e.g. shape, color, hue, size, texture, and orientation) must be carefully elected to adequately represent and correspond with the particular aspect of information to be communicated (Bertin, 1974). The variety of methods available for representing information through cartographic representations allow to create strikingly different results created from a single set of data (Thompson, Lindsay, \& Gaillard, 2011). And yet, while a map may be designed to convey a single dataset of interest, it does not convey a single universal message (Thompson et al., 2011). Chandler even claims that "changing the form of the signifier while keeping the same signified can generate different connotations. Changes of style or tone may involve different connotations, such as when using different typefaces for exactly the same text, or changing from sharp focus to soft focus when taking a photograph” (Chandler, 2007, p.143).

In cartography, semiotic rules (Bertin, 1974) provide a framework to adequately select between the type of visual variables in correspondence to the characteristics of information to be communicated, such as when to represent information by shape, color, or size. These rules, however, do not further differentiate within each type of visual variable, such as regarding the effects of different signifiers in maps on the map readers' associations and interpretations, such as the effect of depicting information by particular shape or color. In other words, while semiotics provides a shared set of signs and rules, it does not address how choices for or the composition of graphic variables may lead to different connotations, interpretations or judgments.

Recent research in cartography has begun to empirically study such effects of design decisions on the map reader's responses. Findings support the notion that changes in visual map styles can influence the map readers' responses, such as towards altering emotional responses, trust, liking, recall, efficiency, and effectiveness (Fabrikant, Christophe, Papastefanou, \& Maggi, 2012; Garlandini \& Fabrikant, 2009; Jenny et al., 2018; Muehlenhaus, 2012). However, empirical findings are still scarce.

This research is therefore dedicated to further disclosing the impact of visual variables on the map reader's responses. Following Chandler's claim (Chandler, 2007), it is tested whether varying the signifier on a map while keeping the same signified will lead to different responses towards the map. Among the most prevalently used visual signifiers in thematic cartographic representations, geometric shapes (e.g. circle, triangles, squares) are a common means to indicate spatiotemporal occurrences. Yet, their significance and effect on map interpretation has not been explored. Hence, this research focusses on two profound questions, i.e. firstly, what are the unique qualities geometric shapes are imbued with?, and secondly, to which extent do cartographic representations, which are altered merely according to their geometric signifiers, involve different affective and cognitive responses towards the map? We claim that the choice of signifier matters, such as the choice for a circular shape (as opposed to a sextant) may influence the map viewer's responses due to the signifier's inherent qualities. Figure 1 illustrates a set of signifiers used in the empirical studies of the present research. 


\section{$\bullet \bullet-0 \Delta \square \bullet \bullet x \star * \bullet$}

Figure 1. Example of stimuli used in the empirical user studies of this research, comprising of 12 geometric shapes.

Empirical studies have been designed and conducted to identify the particular qualities of basic geometric shapes (e.g. qualities of activation, potency, and valence) from a user perspective as well as to identify and quantify (dis)similarities of geometric shape stimuli, commonly used in visual communication and in particular in thematic cartographic representations. The concept of similarity is of crucial importance to theories in cognitive sciences, revealing part of the stimuli' cognitive structures and relatedness. In a second step of this research, further empirical studies have been conducted to test the impact of the previously identified shape qualities and (dis)similarities on map interpretation and map related judgments. Current findings strongly support the notion that even basic geometric shapes imbue particular qualities, affecting map connotations, associations, and judgments.

By unravelling hidden communication effects and cognitive structures of graphic variables, this research indicates significant implications in the context of cartography and beyond. In research and practice, it is particularly beneficial to appropriately discriminate between stimuli in order to take informed choices. This research aims to contribute to a more holistic understanding concerning the effects of design decisions and to contribute to more effectively communicating messages by deliberately applying visual variables with distinct qualities.

\section{References:}

Bertin, J. (1974). Graphische Semiologie: Diagramme, Netze, Karten. Berlin, New York: Walter de Gruyter.

Chandler, D. (2007). Semiotics: The basics. Routledge.

Fabrikant, S. I., Christophe, S., Papastefanou, G., \& Maggi, S. (2012). Emotional response to map design aesthetics. In 7th International Conference on Geographical Information Science (pp. 18-21). Columbus, Ohio.

Garlandini, S., \& Fabrikant, S. I. (2009). Evaluating the Effectiveness and Efficiency of Visual Variables for Geographic Information Visualization. LNCS, 5756, 195-211.

Jenny, B., Stephen, D. M., Muehlenhaus, I., Marston, B. E., Sharma, R., Zhang, E., \& Jenny, H. (2018). Design principles for origin-destination flow maps Design principles for origin-destination flow maps. Cartography and Geographic Information Science, 45(1), 62-75. https://doi.org/10.1080/15230406.2016.1262280

Keates, J. S. (1996). Understanding Maps (2nd ed.). Addison Wesley Longman Limited.

Krauss, R. M. (2002). The Psychology of Verbal Communication.

Langer, S. K. (1953). Feeling and form - a theory of art. New York: Charles Scribner's Sons.

MacEachren, A. M. (1982). The Role of Complexity and Symbolization Method in Thematic Map Effectiveness. Annals of the Association of American Geographers, 72(4), 495-513.

Monmonier, M. (1996). How to Lie with Maps. Chicago: The University of Chicago Press.

Muehlenhaus, I. (2012). If Looks Could Kill: The Impact of Different Rhetorical Styles on Persuasive Geocommunication. The Cartographic $361-375$. https://doi.org/10.1179/1743277412Y.0000000032

Russell, J. A. (1980). A Circumplex Model of Affect. Journal of Personality and Social Psychology, 39(6), 1161-1178.

Russell, J. A., \& Feldman Barrett, L. (1999). Core affect, prototypical emotional episodes, and other things called emotion: dissecting the elephant. Journal of Personality and Social Psychology, 76(5), 805-819.

Thompson, M. A., Lindsay, J. M., \& Gaillard, J. (2011). The influence of probabilistic volcanic hazard map properties on hazard communication. https://doi.org/10.1186/s13617-015-0023-0

Wood, D. (2010). Rethinking the power of maps. Guilford Press. 